\title{
Integrity performance assessment of a Closed System Transfer Device syringe adaptor as a terminal closure for Luer-Lock syringes
}

\author{
Kate E Walker ${ }^{1}$, Romana Machníková ${ }^{1}$, Laima Ozolina ${ }^{1}$, Alan-Shaun Wilkinson ${ }^{1}$, Andrew J Johnson ${ }^{1}$, \\ Navneet Bhogal ${ }^{2}$, Kate Pegg ${ }^{2}$ \\ ${ }^{1}$ Biopharma Stability Testing Laboratory, BioCity Nottingham, Nottingham, UK \\ ${ }^{2}$ University Hospitals of Derby and Burton NHS Foundation Trust, Derby, UK
}

\section{ABSTRACT}

Objectives

To investigate the container closure integrity of a Closed System Transfer Device syringe adaptor lock in combination with disposable Luer-Lock syringes as the terminal closure device. The UK NHS Pharmaceutical Quality Assurance committee requires syringe integrity data for final storage devices of aseptic products such as chemotherapy drugs when prepared in advance and stored prior to use as is standard practice for dose banded drugs. The assessment comprised both physical and microbial integrity testing of the combination closed system/ Luer-Lock syringes containers at syringe sizes: $1 \mathrm{~mL}, 20 \mathrm{~mL}$, and $50 \mathrm{~mL}$.

\section{Methods}

Integrity testing was performed as described in the NHS Pharmaceutical Quality Assurance Committee Yellow Cover Document $2^{\text {nd }}$ edition 2013 with Chemfort ${ }^{\mathrm{TM}}$ (Simplivia, IL) syringe adaptor lock devices as replacement for sterile blind hubs. Microbiological integrity was assessed according to Method 1 part 1.4 using Brevundimonas diminuta at $32^{\circ} \mathrm{C}$ for up to 14 -days contact time. Physical integrity was assessed using Method 3 of the yellow cover document which is a dye intrusion method. Dye intrusion was assessed both visually and using a validated ultraviolet-visible spectrophotometer method.

\section{Results}

Chemfort ${ }^{\mathrm{TM}}$ syringe adaptor lock/ Luer-Lock syringe combinations were shown to be: (1) free of microbiological contamination after 14-days contact time, (2) free of dye intrusion at all syringe sizes tested ( $n=61$ in total). The data demonstrates $100 \%$ closure integrity of the final container system when Chemfort ${ }^{\mathrm{TM}}$ syringe adaptor lock replaces the syringe hub as the terminal closure device.

\section{Conclusions}

Syringe adaptor lock components complied with the NHS Pharmaceutical Quality Assurance Committee Yellow Cover Document syringe integrity requirements when used as the terminal closure of Luer-Lock disposable syringes from $1 \mathrm{~mL}$ up to $50 \mathrm{~mL}$. Therefore, syringe adaptor lock (Chemfort ${ }^{\mathrm{TM}}$ ) can be used as the terminal closure system for pre-filled syringes of chemotherapeutic drug products prepared in advance in UK NHS Pharmaceutical Technical Services. 


\section{INTRODUCTION}

Hazardous drugs (HDs) such as antineoplastics are routinely prepared in hospital pharmacy and used in the treatment of patients suffering from various forms of cancer, the scale of which is increasing due to longer life expectancy amongst the population worldwide. ${ }^{1,2}$ However, whilst there is a defined benefit to the patient, accidental exposure of the healthcare workers to the same HDs can result in harm with no associated benefits. ${ }^{3,4}$

Anecdotal evidence suggests that health workers are becoming harmed by accidental exposure to HD materials and this is the subject of a number of papers and reviews, with the risk of exposure to healthcare workers prompting many countries to develop guidelines for safer handling of hazardous drugs. ${ }^{4-6}$ One intervention that has the potential to reduce unintended occupational exposure to HDs is the use of closed system transfer devices (CSTD's). ${ }^{7-9}$

Closed system transfer device (CSTD) components are designed to allow safe transfer of hazardous drug materials, thereby minimising healthcare worker exposure both during drug preparation and administration. CSTD's are defined by NIOSH as "a drug transfer device that mechanically prohibits the transfer of environmental contaminants into the system and the escape of hazardous drug or vapor concentrations outside the system". ${ }^{3}$ Two CSTD technologies exist in the market, and both prevent accidental release of aerosols, vapour and liquids: (1) physical barrier and (2) air filtration technology. ${ }^{10,11}$ Recently USP<800> was introduced which is the only pharmacopeia that mandates for CSTDs to be used in hazardous drug administration and recommends their use for drug preparation. ${ }^{12}$ In the UK, the NHS Pharmaceutical Quality Assurance (NHSPQA) committee has recently published guidance advocating the use of CSTD syringe components as replacement of the storage cap immediately prior to connection to the patient for cytotoxic chemotherapy administration. ${ }^{13}$ The guidance document also states that IV bags should be of the needle free variety or be spiked with closed system devices for safe handling of cytotoxic drugs in clinical areas. ${ }^{13}$ The NHSPQA guidelines specifically requests manufacturers of CSTDs to provide necessary device integrity data along with product compatibility and stability data to "enable closed system syringe caps to be able to be added in aseptic services". ${ }^{13}$ Adding CSTD components as part of the final closure system for pre-filled syringes in pharmacy technical services (PTS) reduces the potential for accidental exposure to nursing staff when removing the syringe cap prior to administration as this represents an "open" system. A recent study by Sessink et. al. reports a significant reduction in exposure when syringe caps are replaced with CSTD components on the ward prior to administration compared with no CSTD. ${ }^{9}$ The current UK guidance where syringe caps are replaced by CSTD components on the ward prior to administration involves "opening" the system and therefore creates potential for exposure. ${ }^{13}$ Therefore there is an urgent operational need for device integrity data relating to CSTD components when used in combination with syringes to enable CSTD components to be added in PTS during compounding rather than at ward level.

In the UK, the gold standard for testing of syringe integrity is the NHSPQA yellow cover guidance document $(Y C D){ }^{14}$ The $Y C D$ requires that both microbiological and physical integrity tests are performed on the container closure system to assess integrity. Microbiological sterility testing of media fills $(n=20)$ must be performed following immersion of the container in a culture broth according to either method 1 or 2 of the YCD. ${ }^{14}$ Method 2 has a short contact time of 30 minutes and employs Escherichia coli as the challenge agent. In the present study method 1 was selected which has an extended contact time of 14 -days at temperature of $30-35^{\circ} \mathrm{C}$ and uses the challenge organism Brevundimonas diminuta which provides for a more stringent test of integrity. ${ }^{14}$ The test for physical integrity (Method 3) of the closure device is a dye intrusion test using methylene blue dye with the devices rotated for 2 hours whilst immersed in a solution of the dye. ${ }^{14}$ The 
physicochemical and microbial tests described in the NHS YCD share significant commonality with other methods described within USP $<1207>$ and European Pharmacopeia (Ph. Eur. 3.2.9) for container closure integrity $(\mathrm{CCl})$ testing. ${ }^{15-17}$

For adoption of CSTD components in PTS in the UK, syringe adaptor components must be tested to meet the NHS YCD standards for syringe integrity testing, whereby the syringe adaptor component replaces the sterile blind hub as the terminal closure. ${ }^{13}$ The present study aims to address this capability gap and facilitate the adoption of SAL closed system device components within PTS as replacement for syringe hubs with concomitant benefits in reduction to healthcare worker and nurse exposure. . $^{13,18-19}$

\section{MATERIALS AND METHODS}

\section{Materials}

Chemfort ${ }^{\mathrm{TM}}$ Syringe Adaptor Lock (SAL) (MG245277, Simplivia Healthcare Itd, Kiryat Shmona, IL) were used as the tested CSTD components in this study. Chemfort ${ }^{\mathrm{TM}}$ Vial Adaptor (VA) (MG245248, Simplivia Healthcare Itd, Kiryat Shmona, IL) were used to allow draw up of media. All manipulations of the Chemfort ${ }^{\mathrm{TM}}$ SAL and VA were performed in accordance with the manufacturer's instructions for use (IFU). ${ }^{19}$ Becton Dickinson (BD) disposable Luer Lock (LL) syringes of sizes: $1 \mathrm{~mL}$ (10630694, Fisher UK) , 20mL (10569215, Fisher UK) and 50mL (10636531, Fisher UK) were assessed as drug containers. Single strength tryptic soya broth (TSB) (Cherwell Laboratories, Bicester, UK) was used as the growth media. Sterile blind hubs were used for control devices (BD, UK). Brevundimonas diminuta (ATCC 11568) was supplied by LGC Standards in the UK. TSA $90 \mathrm{~mm}$ plates (IRR Cherwell, UK) and TSA + Neutraliser number $460 \mathrm{~mm}$ plates (IRR Cherwell, UK) were used for growth of cultures. Prochlor 8-hour sporicidal wipes (Contec, UK), IMS 70\% Alcohol wipes (Helepet, UK), sterile wipes (individually wrapped) (Helapet, UK) and IMS 70\% Ethanol spray (Helapet, UK) were used for disinfection. 3,7-bis(Dimethylamino)-phenothiazin-5-ium chloride (methylene blue) dye (0.4\%) CAS 61-73-4 (Sigma Aldrich, UK) was used for dye intrusion testing. MilliQ $>18$ Mega Ohm purified water was generated prior to use (Elix Merck Millipore, UK). Small split cotter pins and wood screws were used to secure the syringe plungers (Machine Mart, UK) and Leifheit storage containers were used for immersion of devices (Amazon, UK) for dye intrusion testing. Uv-vis grade flat bottomed 96 microwell plates were used for absorbance reading all solutions from dye intrusion tests (Fisher, UK).

Equipment

Spectrometer Epoch plate reader (Biotek, UK) was used to measure absorbances at $660 \mathrm{~nm}$. Roller mixer (Stuart SRT9D, Fisher, UK) was used for dye intrusion tests. LEC incubators (300WNP, LEC UK) and (300NP, LEC UK) were used for incubation of all cultures.

Method 1. Microbiological integrity using Brevundimonas diminuta: Partial immersion testing.

All testing was performed as described in the NHS YCD - Method 1 sub section 1.4 for partial immersion and according to device IFU. ${ }^{13,18-19}$ Disposable BD syringes $(1,20$ and $50 \mathrm{~mL}$ ) were connected to Chemfort ${ }^{\text {TM }}$ SALs (20 units for each syringe size). Single strength tryptic soya broth (TSB) was withdrawn into each syringe and SAL combination unit from a media fill vial $(100 \mathrm{~mL})$ prefitted with Chemfort ${ }^{\mathrm{TM}}$ vial adaptor. All SAL septa were punctured three times including first puncture to withdraw the media into the body of the syringe by mating the SAL with the corresponding vial adaptor component. These three punctures of the septa were performed to present an additional challenge to the CSTD component. Following draw up of the media the devices 
were disinfected (two-step process) following Quality Assurance of Aseptic Preparation Services (QAAPS) protocols and incubation for 7-days at $20-25^{\circ} \mathrm{C}$ followed by 7 -days at $30-35^{\circ} \mathrm{C}$ to ensure sterility of the TSB in the syringes, prior to testing. ${ }^{20}$ All test articles that were shown to be free of growth were released for testing in the study at the end of the 14-day quarantine period. All test devices were partially submerged into a vessel containing single strength TSB inoculated with subcultured B. diminuta and incubated for an additional period of 14 -days at $30-35^{\circ} \mathrm{C}$. The devices were then cleaned and inspected for evidence of microbial growth. Positive control devices consisted of a LL syringe of each size in combination with sterile blind hub as the terminal closure device with the hub left partially open. To demonstrate growth promotion capability two test articles that showed no growth of each syringe size were inoculated with TSB that had been contaminated with $B$. diminuta. The inoculated syringes were then incubated for a period of three days at $30-35^{\circ} \mathrm{C}$ and inspected visually for signs of microbial growth.

\section{Method 2. Physical integrity-dye intrusion testing using methylene blue (MB) $0.4 \% \mathrm{w} / \mathrm{v}$}

The test articles comprising LL syringe at each volume size fitted with Chemfort ${ }^{\mathrm{TM}}$ SAL were connected to a Chemfort ${ }^{\mathrm{TM}}$ vial adaptor to allow filling to $75 \%$ of maximum volume with MilliQ water. Each Chemfort ${ }^{\mathrm{TM}}$ SAL septa were punctured in total three times prior to testing. These three punctures were performed to provide an additional physical challenge to the SAL CSTD component and were performed by mating the SAL to the corresponding CSTD vial adaptor component in accordance with IFU. ${ }^{19} \mathrm{~A}$ partial internal vacuum was then applied to each test article by pulling out the syringe plunger and securing it using a mechanical screw or pin. Chemfort ${ }^{\mathrm{TM}} \mathrm{SAL}$ plus LL syringe combinations were subsequently placed in a suitable screw topped vessel containing a solution of methylene blue (MB) dye. Each container of test devices represents a single batch. For the smallest syringe size of $1 \mathrm{~mL}$ all twenty test articles were accommodated with positive controls in one batch. For the largest syringe size of $50 \mathrm{~mL}$ a number of batches were tested due to the lower occupancy of the container and hence a positive control was tested in each batch. The test articles were submerged in the dye solution and rotated for a total of 2 hours at $45 \mathrm{rpm}$ on a roller mixer.

Positive control devices $(n=1)$ were included in each batch of testing for all syringe volume sizes and comprised Chemfort ${ }^{\mathrm{TM}}$ SAL / LL syringe combinations in which a single strand of stainless-steel wire (OD $0.4 \mathrm{~mm}$ ) was inserted, running parallel to the barrel between the plunger seal and the inner barrel wall. The presence of the wire introducing a route of access to the internal compartment of the control device. Different total numbers of positive control syringes for the three sizes were used. This was due to the maximum occupancy for each size combination of BD LL syringe within the cylindrical container. One positive control was included per batch of test articles during testing to verify system suitability of the system. Therefore, for the smallest $1 \mathrm{~mL}$ syringe tested in combination with Chemfort ${ }^{\mathrm{TM}}$ SAL only one positive control device was necessary ( $\left.n=1\right)$. At $50 \mathrm{~mL}$ which was the largest syringe size tested five batches of test articles were generated and hence five positive control devices $(n=5)$ were required. For the $20 \mathrm{~mL}$ syringe size 3 batches of test articles were used and hence three positive controls were performed, one per batch $(n=3)$. In total eight positive control tests were performed. Negative controls were performed comprising of all three combinations of $\mathrm{SAL} / \mathrm{LL}$ syringe filled with MilliQ water $(n=1)$ that were left at ambient for 2-hours and not immersed in the dye solution or rotated.

At the end of test the Chemfort ${ }^{\mathrm{TM}}$ / LL syringe combination devices were removed from the dye solution, washed externally and visually inspected for evidence of dye ingress. In addition, a small volume of each syringe's contents was removed for quantification using a uv-vis spectrophotometer and validated spectrophotometric method for quantifying the presence of MB dye solution. 
A microplate reader set to a detection wavelength of $660 \mathrm{~nm}$ was used to read all test solutions in triplicate. Three Quality Control (QC) check standards at low, middle and high concentrations of dye along with MilliQ water (blanks) were read in each plate in triplicate.

The solutions from each syringe combination were analysed in triplicate within the 96-microwell plate. Alongside test solutions, MilliQ water (blank) and the three QC check reference standards (Low, Medium and High) were also analysed in each plate in triplicate. The QC check standards for methylene blue dye were prepared by diluting the $0.4 \% \mathrm{w} / \mathrm{v} \mathrm{MB}$ solution in MilliQ water to the following final MB concentrations: $4 \times 10^{-5} \% \mathrm{w} / \mathrm{v}$ (Low); $0.002 \% \mathrm{w} / \mathrm{v}$ (Medium) and $0.4 \% \mathrm{w} / \mathrm{v}$ (High).

For the microplate readings, the average of triplicate MilliQ water blank data ( $n=3$ ) was subtracted from the average calculated test data $(n=3)$ and the blank corrected results reported for each test device $(n=20)$ comprising the Chemfort ${ }^{\text {TM }}$ SAL / LL syringe components.

The pass criteria for visual inspection of the test devices was that the solution inside should remain clear with no blue dye colouration when compared with MilliQ water reference solution and low QC check standard, with the low QC check standard dye solution providing a reference for visible blue colour ( 1 in 10,000 dilution of $0.4 \% \mathrm{w} / \mathrm{v}$ methylene blue stock solution) at the limit of detection (LOD). The 1:10,000 MB solution was determined at the time of the study to be the lowest dye coloured solutions that could be detected both visually and using a validated spectrophotometer method. All samples from the tested syringe combinations ( $n=20$ for 1 and $50 \mathrm{~mL}$ syringes, $n=21$ for $20 \mathrm{~mL}$ syringes) were visually compared to both MilliQ water (no dye) and to the low concentration QC check standard against a white background. Test devices were assessed as meeting the acceptance criteria for $100 \%$ integrity when in addition to visual inspection spectrophotometric absorbance readings were recorded $\leq 0.010( \pm 0.005) \mathrm{mAu}$ at $660 \mathrm{~nm}$. Where acceptance was not met the result was recorded as a positive for dye ingress.

\section{RESULTS}

Microbiological integrity 
One of each size of $L L$ syringe were fitted to either a blind hub $(n=2)$ as a positive control $(C 1, C 2, C 3)$ or to a Chemfort ${ }^{\mathrm{TM}}$ SAL $(n=20)$ as test article $(T 1, T 2, T 3)$ combinations. Figure 1 below shows the syringe combinations prior to immersion and testing. In figure 1 , both test and control syringe combinations were free of microbial growth after draw up and initial incubation immediately prior to test. At the end of the 14 -day incubation period at $30-35^{\circ} \mathrm{C}$, following the partial-immersion challenge all test combinations were free of microbial growth as can be seen in figure 2 (labelled T1T3). All positive controls (C1-C3) failed to maintain sterility of the high growth TSB media product at the end of 14 -day incubation at $30-35^{\circ} \mathrm{C}$ as can be seen in figure 2 (labelled C1-C3) which shows clear evidence of growth in the control syringe combinations $\mathrm{C} 1-\mathrm{C} 3$. The data demonstrates the ability of Chemfort ${ }^{\mathrm{TM}} \mathrm{SAL} / \mathrm{LL}$ combination container systems to maintain $100 \%$ integrity under the conditions of the YCD microbiological challenge. ${ }^{14}$

Figure 1. All three volume sizes of test Luer-Locksyringes fitted to either a blind hub as a positive control $(\mathrm{C} 1, \mathrm{C} 2, \mathrm{C} 3)$ or to a Chemfort ${ }^{\mathrm{TM}} \mathrm{SAL}$ as test article $(\mathrm{T} 1, \mathrm{~T} 2, \mathrm{~T} 3)$ combinations prior to incubation.

Figure 2. One of each size of $L L$ syringe fitted to either a blind hub as a positive control $(C 1, C 2, C 3)$ or to a Chemfort ${ }^{\mathrm{TM}} \mathrm{SAL}$ as test article $(\mathrm{T} 1, \mathrm{~T} 2, \mathrm{~T} 3)$ combinations post 14 -day incubation at $30-35^{\circ} \mathrm{C}$.

Growth promotion testing demonstrated positive growth of $B$. diminuta in triplicate test devices at each of the three volume syringe sizes tested $(n=9)$ providing evidence of the ability of the growth media to support growth of the challenge organism post testing.

\section{Physical integrity}

Positive controls for all syringe sizes evaluated, tested in combination with SAL resulted in dye intrusion being observed visually and recorded as an absorbance $\geq 0.010( \pm 0.005) \mathrm{mAu}$ at $660 \mathrm{~nm}$ using the spectrophotometer. In every positive control $(n=8)$ a distinct blue colouration was observed inside the control syringes. This demonstrated a failure of container integrity and provided evidence for system suitability of the method to detect a positive breach in integrity resulting in dye intrusion. ${ }^{14}$

All negative control articles $(n=3)$ remained free of blue dye at the end of test and hence demonstrated that any blue colouration in the test items was due to $M B$ dye intrusion from immersion. The negative control articles showed absorbance readings $\leq 0.010( \pm 0.005) \mathrm{mAu}$ at the end of test as determined by a spectrophotometer.

The results from all devices tested and positive controls obtained in this study are presented in

Table 1 below for both visual detection and quantitative absorbance measurements at $660 \mathrm{~nm}$.

Table 1. Summary of the Spectrophotometric data $(660 \mathrm{~nm})$ and visual appearance data for test Chemfort ${ }^{\text {TM }}$ SAL/ LL syringe combination and control blind hub/ syringe combinations.

Test Chemfort ${ }^{\text {TM }}$ SAL/ LL syringe combination results

Control blind hub/ LL syringe combination results

\begin{tabular}{|c|c|c|c|c|c|c|c|c|c|c|}
\hline $\begin{array}{c}\text { Test } \\
\text { syringe } \\
\text { size }\end{array}$ & $\begin{array}{c}\text { Average } \\
\text { absorbance } \\
\text { at } 660 \mathrm{~nm} \\
(\mathrm{n}=20)\end{array}$ & $\begin{array}{c}95 \% \\
\mathrm{Cl}\end{array}$ & $\begin{array}{c}\text { Units } \\
\text { tested } \\
\text { (n) }\end{array}$ & $\begin{array}{l}\text { Spectrometer } \\
\text { Pass/Fail }\end{array}$ & $\begin{array}{c}\text { Visual } \\
\text { Pass/Fail }\end{array}$ & $\begin{array}{c}\text { Average } \\
\text { absorbance } \\
\text { at } 660 \mathrm{~nm}\end{array}$ & $\begin{array}{c}95 \% \\
\mathrm{Cl}\end{array}$ & $\begin{array}{c}\text { Units } \\
\text { tested } \\
\text { (n) }\end{array}$ & $\begin{array}{l}\text { Spectrometer } \\
\text { Pass/Fail }\end{array}$ & $\begin{array}{c}\text { Visual } \\
\text { Pass/Fail }\end{array}$ \\
\hline
\end{tabular}


It is made available under a CC-BY-ND 4.0 International license .

\begin{tabular}{|c|c|c|c|c|c|c|c|c|c|c|}
\hline $50 \mathrm{~mL}$ & -0.004 & 0.001 & 20 & Pass & Pass & 3.352 & 1.094 & 5 & Fail & Fail \\
\hline $20 \mathrm{~mL}$ & -0.004 & 0.001 & 20 & Pass & Pass & 1.944 & 4.682 & 3 & Fail & Fail \\
\hline $1 \mathrm{~mL}$ & -0.005 & 0.002 & 20 & Pass & Pass & 0.048 & $\mathrm{~N} / \mathrm{A}$ & 1 & Fail & Fail \\
\hline
\end{tabular}

All of the individual 96-microwell plate data for the test Chemfort ${ }^{\mathrm{TM}} \mathrm{SAL} / \mathrm{LL}$ syringe combination and control blind hub/ LL syringe combinations are presented in the supplemental material section, Table S1 and Table S2.

\section{DISCUSSION}

This study demonstrates that a CSTD syringe adaptor can be used as a direct replacement of a sterile blind hub as the terminal closure system for pre-filled syringes containing chemotherapy drug products prepared in aseptic compounding centers where advanced preparation and extended storage of the aseptic product is required. The data presented fulfills the requirements of the NHSPQA guidance requirements around sterility data to support the addition of closed system components to pre-filled syringes in aseptic compounding units in the UK. ${ }^{13}$ Full integrity of the combination container comprising Chemfort ${ }^{\mathrm{TM}} \mathrm{SAL} / \mathrm{LL}$ syringe was demonstrated at all three syringe size combinations with no route of access for microbial or physical contamination of the product.

There are three potential routes of entry for external contaminants to access the internal space of the Chemfort ${ }^{\mathrm{TM}} \mathrm{SAL} / \mathrm{LL}$ syringe combination device: (1) through the luer-to-luer connection between the SAL and commercial LL syringe, (2) through the puncture site of the SAL septa and (3) through the rear of the syringe between the plunger and barrel. In this study routes 1 and 2 were assessed in the microbiological arm of the study and routes 1, 2 and 3 were assessed in the physical arm. The SAL septa were deliberately punctured a total of three times prior to testing, to represent a worstcase scenario. The presence of a puncture site within the septa allows a potential route of access to the internal space of the SAL/ LL syringe combination device. Even after three punctures of the septa of the SAL container closure integrity was demonstrated and found to be $100 \%$ in both the microbiological and physical tests.

As the luer-to-luer connection is stringently assessed in both arms of this study the outcomes demonstrate conclusively that the luer-to-luer connection of a 2-piece combination device (CSTD/ LL syringe combination device) is equivalent in device integrity to a syringe device with no luer-to-luer connection present.

No prior published data exists regarding integrity testing of syringe adaptor CSTD components as part of a final container system performed to YCD standards. ${ }^{13}$ However, there are published studies that report on microbiological integrity testing of CSTD components using different microbial challenge study designs. ${ }^{21-24}$ all report the efficacy of CSTDs to resist a specific microbial challenge applied to the septa prior to connecting components. The data reported by each author as a microbial ingress test is essentially a microbial assessment for container integrity where the container system comprises CSTD components. In each study microbial contamination of the septa of the vial adaptors is followed immediately by a cleaning step prior to connection of the CSTD components. As such these microbial challenge studies report the efficacy of the cleaning procedure 
employed and not the ability of the CSTD components to resist microbial ingress. In the present study a motile organism was employed with the devices immersed over an extended contact time of 14-days at an incubation temperature of $30-35^{\circ} \mathrm{C}$ allowing optimum growth of the $B$. diminuta challenge organism. This combined with three punctures of the septa membranes prior to immersion represents an extreme challenge for the Chemfort ${ }^{\mathrm{TM}} \mathrm{SAL} / \mathrm{LL}$ syringe combination container system. Furthermore, the challenge organism length scale is of the order of a few nanometers which in combination with its high motility makes it very effective at identifying breaches in sterile container systems. Finally, it is noteworthy that all published microbial ingress studies on CSTD components have focused exclusively on the CSTD septa membranes whereas the present study assessed overall device integrity from multiple-points of entry. ${ }^{21-24}$

McMichael et al. reports microbial integrity testing of PhaSeal (BD) components using media fill vials when accessing the vials over 7 days. ${ }^{25}$ However, all manipulations were performed in an ISO 5 environment where there is not expected to be a microbial challenge to the devices. As such the study reported here is the first study to report an actual microbial challenge to a CSTD component (syringe adaptor lock) when used as part of a terminal container closure system.

CSTD's are defined by NIOSH as "a drug transfer device that mechanically prohibits the transfer of environmental contaminants into the system and the escape of hazardous drug or vapor concentrations outside the system". ${ }^{3}$ In order to meet the definition a device should demonstrate : (a) no hazardous drug can escape out from the system, (b) no environmental contamination can cross the system boundary. ${ }^{3}$ The authors have previously published data on and demonstrated system performance of Tevadaptor ${ }^{\mathrm{TM}}$ CSTD components (Chemfort ${ }^{\mathrm{TM}}$ is the second generation of Tevadaptor ${ }^{\mathrm{TM}}$ ) when assessed according to the draft $2016 \mathrm{NIOSH}$ test protocol. ${ }^{11}$ Identical containment information has been proven and is available on file for Chemfort ${ }^{\text {TM }}$ (unpublished data). The combined studies fulfil part (a) of the NIOSH CSTD requirement. ${ }^{3}$ The results reported in the present study provides the evidence that Chemfort $^{\mathrm{TM}}$ satisfies part (b) of the NIOSH CSTD definition and adds to the body of evidence that demonstrates Chemfort ${ }^{\mathrm{TM}}$ being capable of preventing environmental contamination and maintains a sterile barrier when used as part of a final container system. ${ }^{3}$

The data supports the use of Chemfort $^{\text {TM }}$ syringe adaptor lock (SAL) to be used within aseptic compounding units in combination with Luer-Lock syringes (BD, UK) for extended storage of aseptically compounded sterile products used in chemotherapy including dose banded products. ${ }^{13}$

Current practice in UK pharmacy technical services involves the use of a sterile blind hub as closure for pre-filled syringes used on aseptic products prepared in advance and stored over extended time periods including chemotherapeutic drugs. ${ }^{13}$ Dose banding of parenteral chemotherapeutic drug products where patient-individualised doses are rounded up or down to predetermined banded doses has been successfully implemented for a number of years in the UK. ${ }^{26-27}$ Banding of chemotherapy doses offer several advantages for the hospital aseptic compounding unit including: reduced patient waiting times, reduction in chemotherapy waiting times, and reduction in drug wastage. However, to leverage economic and patient outcome advantages of advanced aseptic compounding of chemotherapy using dose banding of pre-filled syringes requires: (1) access to extended drug stability data for the drug product, (2) a compounding environment and systems in place for quality control and quality assurance and (3) container integrity data for the final storage device which in the case of a pre-filled syringe is typically a sterile blind hub. ${ }^{13}$ Drug stability testing is outside of the scope of this study. The present study for the first time reports syringe integrity data for a CSTD component (Chemfort ${ }^{\mathrm{TM}} \mathrm{SAL}$ ) to be used with Luer-Lock syringes (BD) as part of the final 
container system in pharmacy technical services (PTS) allowing the addition of CSTD components as part of dose banding in the UK.

\section{CONCLUSIONS}

This study reports the testing of Chemfort ${ }^{\mathrm{TM}}$ SAL CSTD components when combined with $1 \mathrm{~mL}, 20 \mathrm{~mL}$, and $50 \mathrm{~mL}$ Luer-Lock(BD, UK) syringes in accordance with the NHS yellow cover document (YCD) for syringe integrity and fulfils the requirements of the NHSPQA requirements for addition of CSTD components to pre-filled syringes in UK aseptic compounding units. ${ }^{13}$ All 60 combinations of Chemfort ${ }^{\text {TM }}$ SAL device demonstrated $100 \%$ integrity across both the microbiological and physical integrity tests. The results support the suitability of Chemfort $^{\mathrm{TM}} \mathrm{SAL}$ as a terminal closure device for BD LL syringes in aseptic pharmacy technical services. The present study provides the evidence to support Chemfort ${ }^{\mathrm{TM}}$ SAL components being added within aseptic services and will be most impactful within compounding centres performing dose banding of chemotherapy drugs where the addition of closed system components as recommended by UK NHSPQA guidelines provide for a safer administration space helping to protect health workers from accidental occupational exposure when handling pre-filled syringes. ${ }^{3-5}$

\section{Acknowledgements and Affiliations}

The work described was performed in accordance with a research grant from Simplivia Healthcare www.Simplivia.com. The authors would like to acknowledge Simplivia Healthcare for the kind donation of the Chemfort ${ }^{\mathrm{TM}}$ medical devices which were used in the testing and for financial assistance in the form of a research grant to support the work. The authors have no conflict of interest and are all either employed directly by BSTL or sub-contracted under a collaboration agreement.

\section{References}

1. Stewart BW, Wild CP. International agency for research on cancer. World cancer report. 2014.

2. World Health Organization, International Agency of Research on Cancer . GLOBOCAN 2012: Estimated Cancer Incidence, Mortality and Prevalence Worldwide in 2012. In. IARC, Lyon, France, 2013. [database] URL: http://globocan.iarc.fr/Pages/fact_sheets_cancer.aspx (Accessed $19^{\text {th }}$ December 2013)

3. National Institute for Occupational safety and health. Preventing Occupational Exposure to Antineoplastic and Other Hazardous Drugs in Health Care Settings. Safety And Health. 2004. http://www.cdc.gov/niosh/ (Accessed $10^{\text {th }}$ December 2020)

4. Connor T.H., DeBord G.D., Pretty J. R., et al. Evaluation of Antineoplastic Drug Exposure of Health Care Workers at Three University-Based US Cancer Centers, J Occup Environ Med 2010;52;10191027. doi: 10.1097/JOM.0b013e3181f72b63

5. Vyas N, Yiannakis D, Turner A, et al. Occupational exposure to anti-cancer drugs: A review of effects of new technology. J Oncol Pharm Pract 2014;20;278-287.

http://www.ncbi.nlm.nih.gov/pubmed/23975555

6. Mathias PI, MacKenzie BA, Toennis CA et al. Survey of guidelines and current practices for safe handling of antineoplastic and other hazardous drugs used in 24 countries. J Oncol Pharm Pract 2019;25;148-162. 
7. Vyas N, Turner A, Clank JM et al. Evaluation of a closed-system cytotoxic transfer device in a pharmaceutical isolator, J Oncol Pharm Pract 2016;22;10-19. doi: 10.1177/1078155214544993

8. Sessink PJM, Nyulasi T, Haraldsson ELM et al. Reduction of Contamination with Antibiotics on Surfaces and in Environmental Air in Three European Hospitals Following Implementation of a Closed-System Drug Transfer Device. Ann Work Expo Heal 2019;63;459-467.

9. Marler-Hausen $\mathrm{T}$, Holt $\mathrm{C}$, Headley $\mathrm{C}$ et al. Use of a closed-system drug transfer device reduces contamination with doxorubicin during bolus injection. Br J Nurs 2020;29;515-21.

10. Nygren O, Olofsson E, Johansson L, Spill and leakage using a drug preparation system based on double-filter technology. Ann Occup Hyg 2008;52;95-98.

11. Wilkinson AS, Allwood MC, Morris CP et al. Performance testing protocol for closed system transfer devices used during pharmacy compounding and administration of hazardous drugs. PLOS ONE 2018;13;1-15.

12. Pharmacopeia US. USP General chapter $<800>$ Hazardous drugs-handling in healthcare settings. 2019. https://www.usp.org/compounding/general-chapter-hazardous-drugs-handling-healthcare. (Accessed $10^{\text {th }} 2020$ )

13. Santillo M, Field A, Henderson J, NHS Pharmaceutical Quality Assurance Committee. Guidance on handling of injectable cytotoxic drugs in clinical areas in NHS hospitals in the UK. NHS Pharmaceutical Quality Assurance Committee, London. 2018. https://www.sps.nhs.uk/wpcontent/uploads/2018/07/Guidance-on-Handling-Cytotoxics-Ed-1-July-2018.pdf (Accessed December $10^{\text {th }} 2020$ )

14. NHS Pharmaceutical Quality Assurance Committee. Protocols for the Integrity Testing of Syringes, edn 2, 2013. https://pasg.nhs.uk/downloads.php?did=266 (Accessed December $10^{\text {th }}$ 2020)

15. Pharmacopoeia US. USP<1207> Sterile Product Packaging-Integrity Evaluation. 2011.

16. European Pharmacopoeia. 3.2. 9 Rubber closures for containers for aqueous parenteral preparations, for powders and for freeze-dried powders. European Pharmacopoeia 7.0. European Pharmacopoeia. 2010.

17. Peláez SS, Mahler HC, Matter A et al. Closure Integrity Testing of Prefilled Syringes, J Pharm Sci 2018;107;2091-2097. https://doi.org/10.1016/i.xphs.2018.03.025.

18. Simplivia Healthcare. Chemfort syringe adaptor lock (SAL). Technical data sheet. https://www.simplivia.com/files/pdf/Chemfort Specs/Simplivia Chemfort Syringe Adaptor Lock.p df (Accessed 10 ${ }^{\text {th }}$ May 2021)

19. Simplivia Healthcare. Chemfort instructions for use (IFU). https://www.simplivia.com/files/pdf/\%E2\%80\%8FSimplivia \%E2\%80\%8FIFU Chemfort EU.pdf (Accessed $10^{\text {th }}$ May 2021)

20. Beaney AM, editor. Quality Assurance of Aseptic Preparation Services: Standards Handbook. Parts A \& B. Royal Pharmaceutical Society; 2016.

21. DePrijck K, D'Haese E, Vandenbroucke J et al. Microbiological challenge of four protective devices for the reconstitution of cytotoxic agents. Lett App/ Microbiol 2008;47;543-548. 
medRxiv preprint doi: https://doi.org/10.1101/2021.11.11.21266172; this version posted November 14, 2021. The copyright holder for this preprint (which was not certified by peer review) is the author/funder, who has granted medRxiv a license to display the preprint in perpetuity.

It is made available under a CC-BY-ND 4.0 International license .

22. Equashield, A 7 Days Microbial Ingress Test and Assessment for Extending the Beyond Use Date of Single Use Vials Utilizing the EQUASHIELD ${ }^{\oplus}$ Closed System Drug Transfer Device. Nelson Laboratories, Salt Lake City, Utah. 2013. http://rivosem.com.tr/wp-content/uploads/2015/04/A-7Days-Microbial-Ingress-Test-of-Single-Use-Vials-Utilizing-the-EQUASHIELD-Closed-System-DrugTransfer-Device-CSTD.pdf (Accessed $10^{\text {th }}$ December 2020)

23. ICU Medical, "Microbial Ingress Study for ChemoLock ${ }^{\circledR}$ Devices (White paper)," 2014. https://www.icumed.com/media/12787/p20-4875 chemolock microbial ingress wp.pdf (Accessed $10^{\text {th }}$ December 2020)

24. BD-7336 BD PhaSeal Optima Vapor Containment White Paper. https://www.bd.com/documents/white-paper/HDS BD-PhaSeal-Optima-vapor-containmentwhitepaper WP EN.pdf (Accessed 10 ${ }^{\text {th }}$ December 2020)

25. McMichael DM, Jefferson DM, Carey ET et al. Utility of the PhaSeal closed system drug transfer device. Am J Pharm. 2011;3:9-16.

26. Sewell GJ, Kaestner S. Dose-banding of cancer chemotherapy. 2010. http://hdl.handle.net/10026.1/3709.

27. Rashed AN, Tomlin S. Dose-banding limits for commonly prescribed medications for children in the UK. Arc Dis Child 2020;105;30-31. 


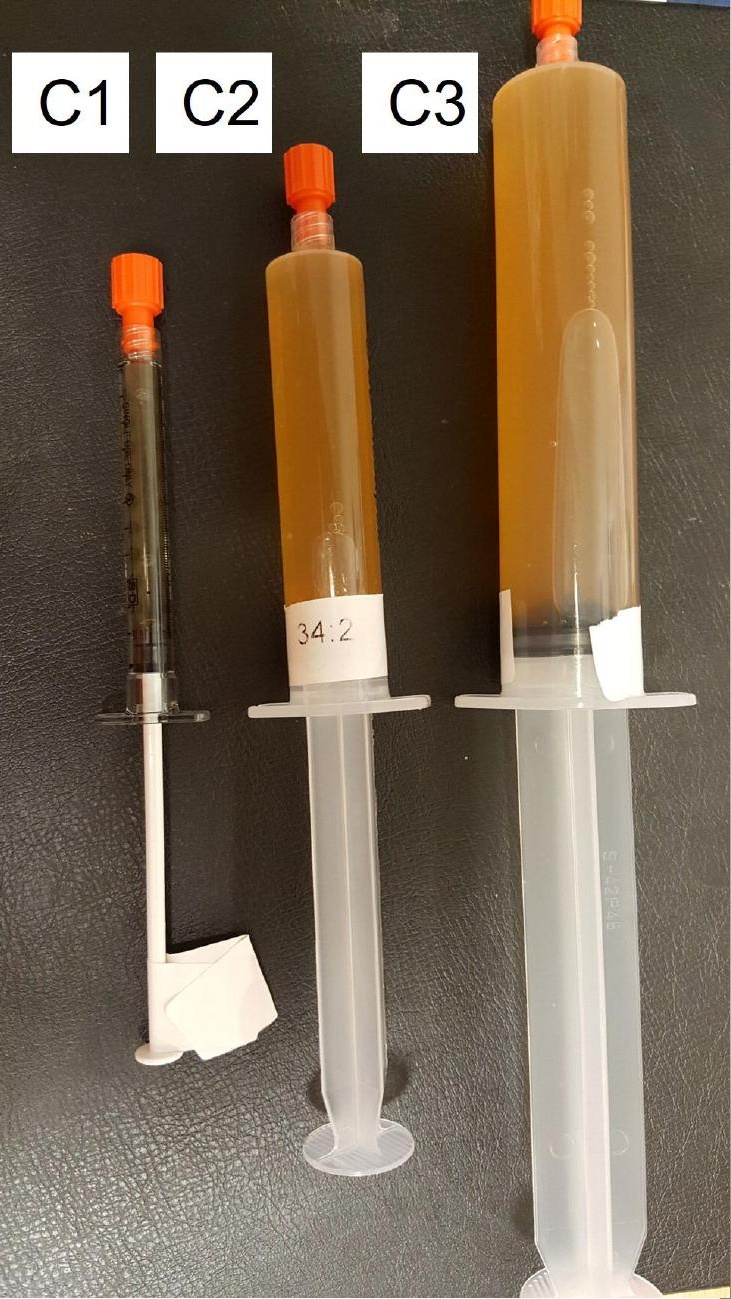

\section{T3}

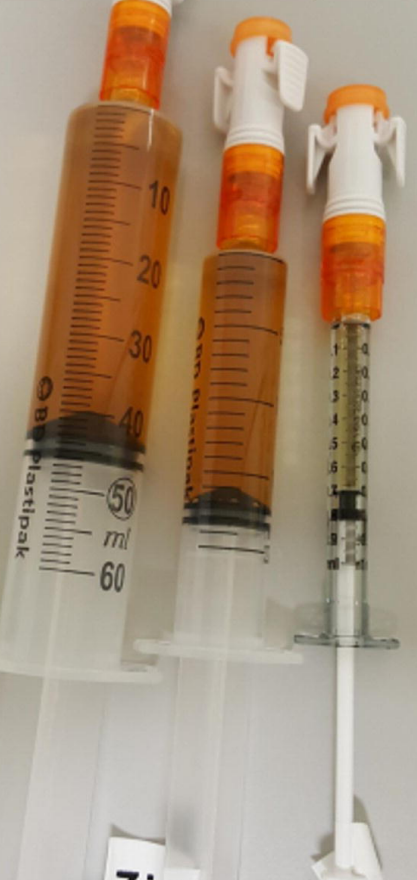

Z: 


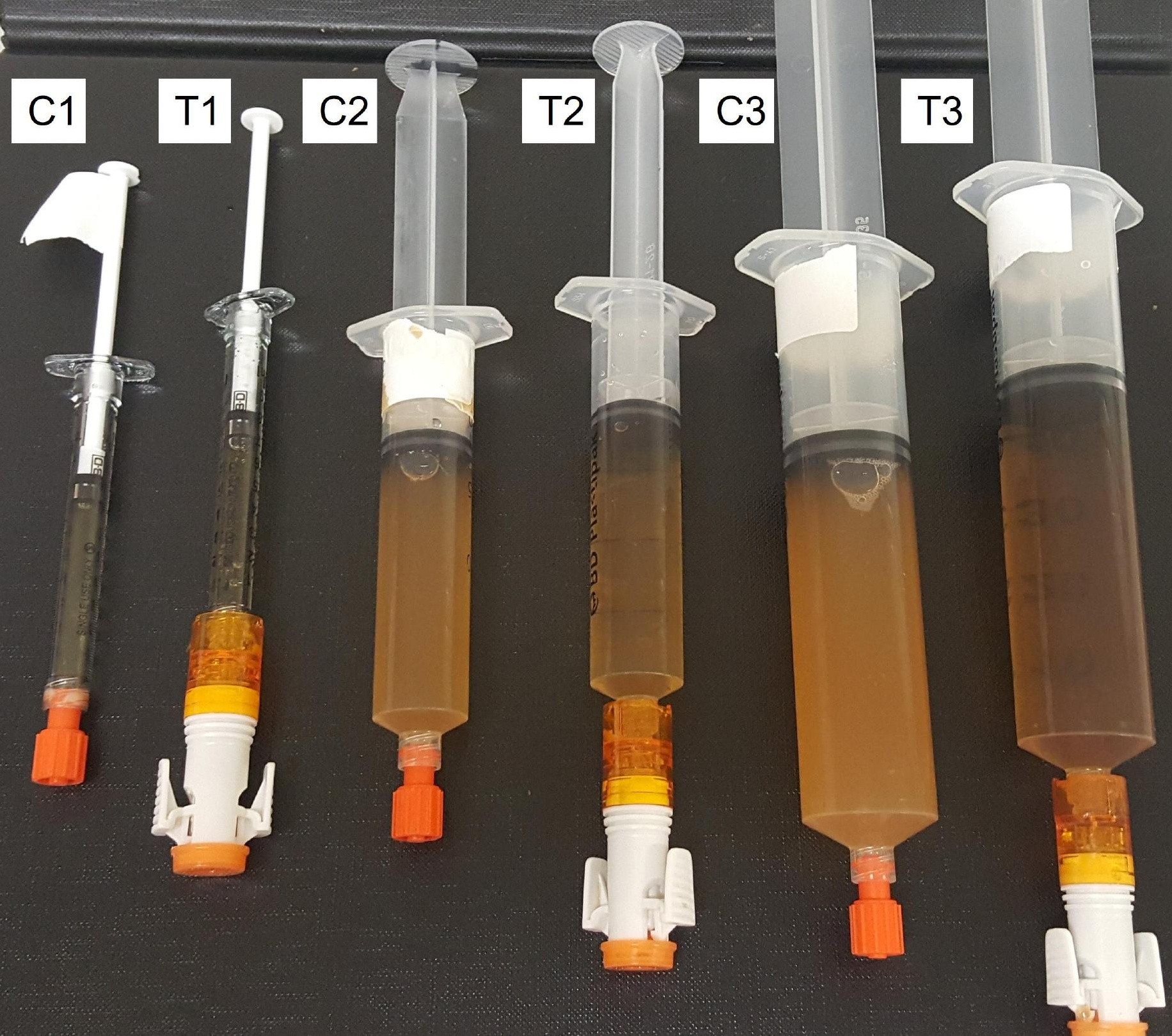

